\title{
The Structured Interview of Family Risk Assessment in Clinical Use: A Study with Parents of Juvenile Offenders in Detention
}

\author{
Diamantino Santos ${ }^{1}$, Isabel Alberto ${ }^{2}$ \\ ${ }^{1}$ Directorate General of Social Rehabilitation and Imprisionment, Centro Educativo dos Olivais, Coimbra, Portugal \\ ${ }^{2}$ Faculty of Psychology and Educational Sciences, University of Coimbra, Coimbra, Portugal \\ Correspondence: Diamantino Santos, Centro Educativo dos Olivais, Rua Brigadeiro Correia Cardoso, n. ${ }^{\circ}$ 73, 3000-086, \\ Coimbra, Portugal.
}

Received: November 7, 2016

Accepted: December 3, 2016

Available online: December 14, 2016

doi:10.11114/ijsss.v5i1.2078

URL: http://dx.doi.org/10.11114/ijsss.v5i1.2078

\begin{abstract}
In the juvenile clinical forensic settings risk assessment, instruments that allow a dynamic understanding of the interaction between family risk and protective factors are needed. This study aims to contribute to the validation of the Structured Interview of Family Risk Assessment (SIFAR) in juvenile clinical forensic practice. Using a quasi-experimental design, the effects of a family program on risk and protective family factors were assessed with SIFAR and the YLS/CMI. Non-parametric methods were used. The participants were a convenience sample of 16 parents ( 8 from a control group and 8 from an experimental group) of detained adolescent male delinquents in Portuguese forensic facilities. The YLS/CMI as an actuarial risk assessment tool and SIFAR as a structured professional judgment toll were used. SIFAR and YLS/CMI showed the effects of the program in reducing the family risk on this sample and the usefulness of the complementary use of both risk assessment tools. The findings show that SIFAR is sensitive to changes in the family assessment risk, allowing the understanding of the family risk and protective factors changes and dynamics, being a suitable instrument for case management.
\end{abstract}

Keywords: delinquency, family, risk factors, protective factors, adolescence

\section{Introduction}

The development of the validation of the Structured Interview of Family Assessment Risk (SIFAR; Santos \& Alberto, 2015; Santos, Alberto, \& Marques, 2016) is a long, diverse and exigent process. Designed as a Structured Professional Judgement (SPJ) tool, the SIFAR intent to assess the multiple dimensions of family life that might constitute a risk or a protective factor on juvenile delinquency, being used as a complement for an actuarial risk instrument like the Youth Level of Service/Case Management Inventory (YLS/CMI; Hoge, Andrews, \& Leschied, 2002).

In this validation process, the evaluation of the SIFAR in clinical use is fundamental to analyze its accuracy and efficacy in case management. For this purpose, developing a research where SIFAR is used in the specific context of application, with high risk detained juvenile offenders, will allow to evaluate its role in the real world of juvenile forensic practice.

A specific risk tool to assess the family risk in delinquency arises from the fact that the family is a key context in the process of human development, with various clinical currents highlighting the role of family in the interaction between individual and contextual factors in juvenile delinquent behavior (Farrington, 2004; Kury \& Woessner, 2002; Le Blanc \& Janosz, 2002; Loeber, Farrington, Stouthamer-Loeber, \& White, 2008). While analyzing the predictors of delinquency, Farrington (2004), Loeber et al. (2008) and Le Blanc and Janosz (2002) concluded for the multidimensionality of causal factors and within these, they stress the importance of the quality of parenting as a determinant of juvenile delinquency.

The studies by Andrews and Bonta (2010), Farrington (2004), Le Blanc and Janosz (2002), Lipsey (2009) and Loeber et al. (2008) point out that there is a complex interplay between the predictors of delinquency and demonstrate that the family can be either a risk or a protective factor in juvenile criminal practice. Particularly, the family risk or protective factors are related to the quality of family relationships (family ties, parental supervision, serious conflicts) and the existence of adolescent relatives with an offending history (Andrews \& Bonta, 2010; Farrington, 2004; Goodman \& Adler, 2010; McGuire, 2004; Welsh \& Farrington, 2010).

In the Portuguese context, Lemos (2007) studied the individual and contextual risk factors for the development of 
psychopathology and delinquent behavior in children/adolescents. These findings demonstrate that the family composition (number of members), relational quality (support, affection, supervision, discipline), social and family circumstances (employment, income and parents' education) interact with the individual characteristics and significant events in childhood to become relevant risk factors to the establishment of adolescent psychopathology and antisocial behavior. Regarding family dynamics, Lemos (2007) found that marital conflict negatively influences the quality of parenting and adolescent perceptions of parental affection. Overall, the results suggest a stronger association between families with poorer parental support and more conflictual interaction patterns and psychopathology in adolescence. As in studies of criminal risk (Andrews \& Bonta, 2010) and in delinquency predictors (Farrington, 2004; Loeber et al., 2008), Lemos (2007) notes that a risk factor has no intrinsic predictive value, but the combination of risk factors increases the likelihood of adolescents developing psychopathology and becoming involved in criminal activity.

In addition to the risk assessment and predictors studies, research about cost-efficacy shows the relevance of family assessment in juvenile delinquency and the efficacy of family intervention in reducing the risk of youth involvement in violence and recidivism. Lipsey (2009) undertook a meta-analysis appraising the technical aspects of the measures of effect sizes like methodology, design, size, sample characteristics, intervention category, and program quality and integrity assessment method. Lipsey (2009) argues that: a) the most effective programs for young offenders are therapeutic interventions (non-punitive, based in cognitive-behavioral, family, group, mixed frame of intervention); b) efficacy is greater in groups with high criminogenic risk; and c) the quality of implementation is directly proportional to the efficiency gains. Lipsey (2009) also concluded that the most effective programs are those with a cognitive-behavioral nature, followed by behavioral, family and orientation programs, but if all variables are controlled, the differences in the effectiveness of these interventions are greatly reduced. In general, programs which addresses the family functioning, supervision, negotiation/conflict resolution and emotional ties (McGuire, 2004) and parental relationship, discipline, relational management and parents' education (Farrington \& Welsh, 2007) show its effectiveness, whereby an adequate and rigorous family risk assessment is relevant in juvenile delinquency.

Once family intervention is so relevant to decrease the risk of criminal involvement or recidivism in adolescence, effective family risk assessment instruments are needed, and this was the aim of the SIFAR development. In fact, if currently there are programs with substantial clinical outcomes like functional family therapy, parenting education (Dembo, Ramírez-Garnica, Rollie, Schmeidler, Livingston, \& Hartsfield, 2001; Gordon, 2002), multisystemic therapy and multidimensional foster care (Henggeler \& Schoenwald, 2011), it is fundamental that the assessment of family variables (risk and protective factors) be performed by adequate and specific instruments.

It is a priority objective of the forensic systems of the Western countries to provide highly effective assessment tools and programs to decrease the probability of adolescent criminal involvement and recidivism. Despite this objective, Henggeler and Schoenwald (2011) concluded that only 5\% of institutionalized youths in the United States have access to effective rehabilitation programs, even given the large need for mental health and education services. Based in the analysis of 600 intervention programs, these authors found that the ones in which efficacy is proved were based on functional family therapy, multisystemic therapy and multidimensional treatment foster care. All of these are programs addressing family variables.

Once the relational and structural family features are such a relevant issue on the juvenile delinquency risk assessment and intervention, it seems that there was a gap in the absence of specific family risk assessment tools. Because of this, the SIFAR emerges as a family risk assessment tool and the main goal of this research is to contribute to its continuous validation process. For this purpose, the SIFAR was applied in a small group of families of detained juvenile offenders, before and after the application of the Risk Reduction Integrated program (RRIP; Pakman, 2007), to assess its clinical use. The RRIP is a program in use in the Portuguese juvenile forensic services to family intervention. Once SIFAR was designed to complement an actuarial risk assessment tool, the Youth Level of Service/Case Management Inventory (YLS/CMI; Hoge, Andrews, \& Leschied, 2002) was also used.

\section{Methods}

This study presents a quasi-experimental design with an experimental group (EG) to which the RRIP (Pakman, 2007) was applied and a control group (CG) without the RRIP. The RRIP efficiency was assessed by a pre-test and a post-test using the YLS/CMI and SIFAR risk assessment tools to analyze the effects of RRIP on the family risk. The RRIP was administered at the Centro Educativo dos Olivais in Coimbra, Portugal, a detention facility for adolescent offenders of the Directorate General of Social Rehabilitation and Imprisonment, between January and July 2013, at a weekend after a parental visit to the young offender, in privacy. The juveniles were informed about the procedures and the aims of the program and agreed that their parents could collaborate. The parents were subsequently informed about the program and invited to participate in this study and all agreed to do so. The control sample was organized to match the family characteristics of the experimental sample on the sociodemographic, economic and risk level, differing by participation 
(EG) or non-participation (CG) in the RRIP. Only the parents participated in the RRIP but both parents and juveniles were assessed by the pre- and post-test risk assessment tools since risk assessment tools must be completed with multiple direct and indirect information resources.

The RRIP was applied by a clinical psychologist who is also a family therapist and the pre- and post-tests were assessed by two external forensic psychologists using the SIFAR and YLS/CMI tools.

\subsection{Sampling}

All participants in both groups were parents of adolescent males complying with the legal custodial measures applied to serious young offenders. The aim of custody is to treat juveniles to reduce the likelihood of future offending, with the RRIP being a program used to reduce family risk for juveniles.

The parents were selected according to the follow criteria: parents who have not attended any structured program intervention or family therapy in the last 24 months up to the date of selection or during this study; parents of adolescent male offenders aged 12 to 18 with a custodial sentence of at least one year and with psychotherapeutic intervention being indicated by the court. The exclusion criteria were: parents diagnosed with severe mental disorder (decompensated mental illness, severe mental retardation, current drug abuse) that compromised joining the program.

The sample consisted of 16 parents of male adolescents who were detained in a juvenile detention centre, who had been referred for psychological intervention by the court and accepted the invitation to participate in the PIRR. The 16 parents were divided into two groups, EG and CG, with 8 in each, and the parent and adolescent participants all signed an informed consent. The equivalence process between EG and CG were extremely challenging, because multiple parent, adolescent and family variables were needed to be compared. It took about one year to find two equivalent groups, fact why the number of participants is too small.

\subsection{Experimental and Control Groups}

EG $(n=8)$ had five female participants, one male and two couples; the predominant marital status was divorced $(n=4)$; there were also one unmarried participant, two married participants and one participant of a remarriage. Six EG participants were parents of the adolescents and two were caregivers. One parent was aged 34, three parents were aged 41-45, two were aged between 51-55 and two were over 60 years old. The minimum age was 34 and the maximum was 75 years old. All the parents were employed $(n=8)$ and only one parent had a criminal record for driving under the influence of alcohol. Seven participants were Portuguese and one was from a Portuguese Speaking African Country (PALOP) / a former Portuguese African territory.

For the adolescents from the EG parents the mode age at onset of antisocial activity was $11(n=3)$, lasting an average of two years $(n=3)$, with crimes against property like theft and robbery predominating $(n=6)$. One adolescent had been convicted of homicide and one other was guilty of parent aggression. All the offences were committed both individually and in groups except for aggression towards parents, which was solely individual.

The CG $(\mathrm{n}=8)$ comprised five female participants, one male and two couples. Two participants were married, two divorced, two remarried and two were single parents. Most of these participants were parents $(n=6)$, and two were caregivers. One parent was 32 years old, two parents were aged 40-45, two were aged 46-50, one was 54, one was 65 and one was 73. The youngest parent was 32 and the oldest 73 years old. Most of the parents were employed $(n=7)$ with only one being unemployed. Only one parent had a criminal record, for driving without a license. In terms of origin, six participants were Portuguese and two were from a PALOP.

The age of onset of antisocial activity of adolescents whose parents were in the CG had was $13(n=4)$, and criminal practice lasted an average of one year $(n=3)$. Crimes against property like theft and robbery predominated $(n=7)$ and one boy was guilty of aggression to parents. These crimes were practiced both individually and in groups $(n=7)$ and only the boy who assaulted his parents engaged in individual criminal practice.

\subsection{Statistics}

SPSS version 17.0 was used to compare the CG and EG. Non-parametric methods were used, particularly the $\chi^{2}$ test with Monte Carlo simulation for the sociodemographic group equivalence. The Wilcoxon-Mann-Whitney test was used to compare results between independent CG and EG samples, and the Wilcoxon test was used for the paired analysis of CG and EG in the pre- and post-test samples. The non-parametric Spearman's rho correlation was used to analyze the association between the SIFAR parenting risk factor and protective factors and the YLS/CMI family context in the post-test sample, using the association reference values from Cohen (1998). A 5\% significance level was used for all statistical analysis. To the effect sizes the $z$-score was used as proposed by Rosenthal, Rosnow and Rubin (2000), with results above the .50 threshold for a large effect. 


\subsection{Intervention Program}

The RRIP (Pakman, 2007) it is a structured intervention program designed to reduce the risk associated with multi-problem families and intervention is at the level of the bio-psycho-social integration of the different family areas: general health, mental health, substance abuse, education, employment, housing and mobility, legal aspects, violence, ethnic/social dissonance, poverty, social networks, social security/disability. With the author's permission the Parenting area was added to respond to the specific intervention needs of an adolescent offender's family dynamics. In an effort to embrace multiple contexts and processes that repeatedly influence these families, the RRIP has been designed to analyze and empower the intra and extra family relational patterns' strengths and decrease the weaknesses by establishing small steps that lead to the reduction of risk in each area. The program is based on a first interview session with parents, which took place in January 2013, followed by three monthly sessions and a final assessment in July, three months after the final session. These monthly sessions work as periodic joint assessments where each category of the program and empowerment was considered with respect to the effectiveness of the intervention and changes wrought by the family (Pakman, 2007).

\subsection{Instruments}

The family risk was assessed by SIFAR (Santos \& Alberto, 2015; Santos, Alberto, \& Marques, 2016) and the YLS/CMI. SIFAR is a SPJ tool designed to assess the family risk of adolescent offenders aged 13 to 18 . SIFAR consists of the parents' and adolescents' equal complementary versions, which are paired to analyze the relational strategy adopted by families to cope with their difficult areas, strengths and their relevant impact on the family. SIFAR is composed of the risk items education, employment, housing/transport, legal problems, social/ethnic dissonance, poverty, social net, social security and parenting conceived as dynamic factors; the factors physical health, mental health, substance abuse, supervision, living in pro-social neighborhood, non-adolescent mother and good relation with pro-social peers are conceived as management factors. The SIFAR risk items assigned are entered on a sheet called "workspace", using a 6-point ordinal scale of growing severity from 0 - difficulties not identified, to 5 - parents and adolescents deny/omit/ignore the difficulty(ies). The protective factors are family involvement, low parental stress, low physical punishment and high discipline, conceived as dynamic factors, coded as dichotomous items ( 0 - absent; 1 - present).

All SIFAR information must be gathered through the interview analysis and other information sources, and entered on a coding sheet called workspace where family risk it is registered and the intervention should be designed and assessed.

The YLS/CMI (Hoge, Andrews, \& Leschied, 2002) it is a structured risk assessment instrument with an actuarial design. It assesses static and dynamic management risk and protective factors and establishes a quantitative estimate for both the general and violent offending by adolescents. It is based on the risk, need and responsivity principles. It assesses a group of factors which are those with highest association with juvenile criminal conduct (Hoge, 2010): history of conduct disorder, antisocial attitudes, values and beliefs, dysfunctional parenting, dysfunctional behavior and personality traits, poor school/vocational achievement, antisocial peer associations and poor use of leisure. The YLS/CMI assesses the protective factors as responsivity factors, that is, as individual/contextual conditions that may facilitate the intervention (Hoge, 2010). The family context risk factor is assessed as a dynamic factor through six items: parental supervision, behavior control, discipline, parental practices, relation with mother and/or father. The family protective factors are family stability and cohesion, parent support and care, support and care from other adults, adolescent attached to mother or some other positive adult model, adequate parent supervision, adequate family economic status, adequate and attractive relational family environment (Andrews \& Bonta, 2010; Hoge, 2010).

\section{Results}

The data analysis started with the equivalence between EG and CG and the results show that EG and CG are equivalent at the sociodemographic and criminal variables, (age of onset, type of crimes, duration of criminality, individual/group crimes, specialization and age of adolescents; gender, age, origin, marital status, marital relations, employment and parents' previous legal problems (Table 1). 
Table 1. Analysis of social, demographic and criminal variables between EG and CG ( $\chi^{2}$, Monte Carlo Simulation, $\mathrm{N}=16$, $\alpha=.01)$.

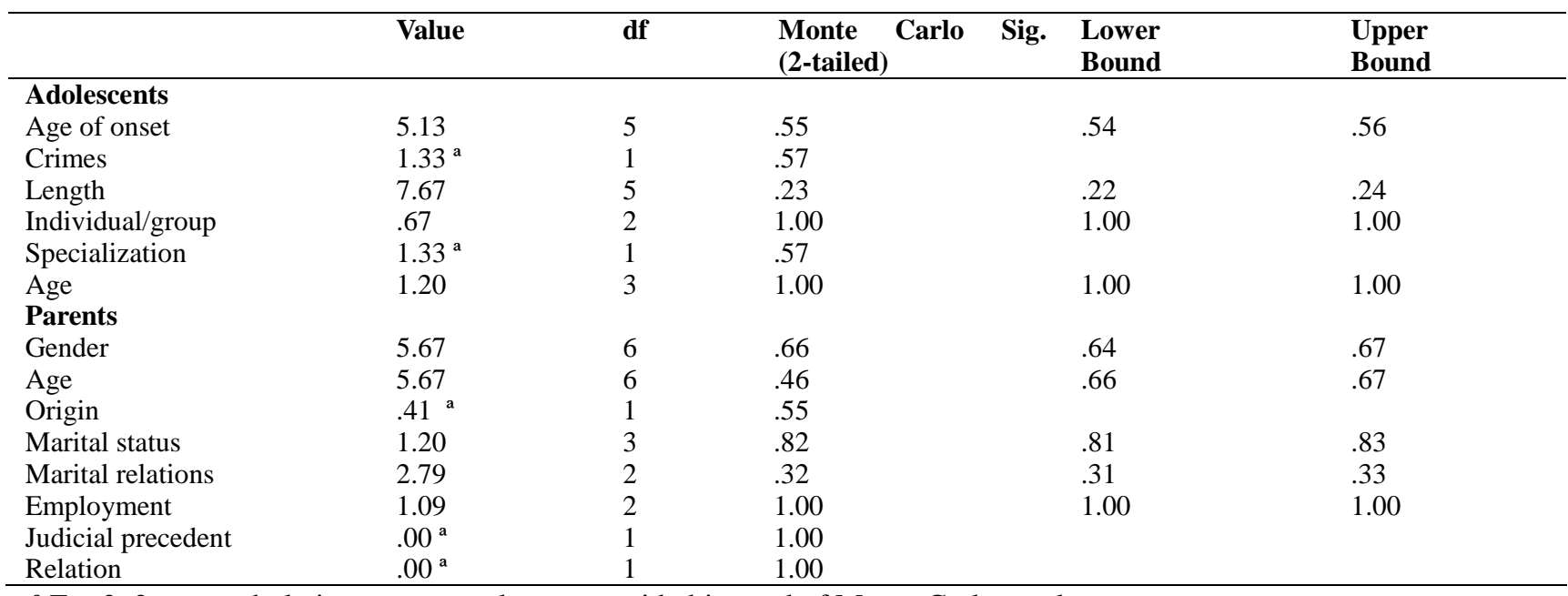

${ }^{\text {a }}$. For $2 \times 2$ cross tabulation, exact results are provided instead of Monte Carlo results.

The equivalence was also analyzed for the risk and protective items, through the SIFAR and YLS/CMI tools. The results in table 2 show that the adolescents do not exhibit significant differences in their risk level items, so it could be considered that there is a global equivalence between EG and CG (5\% significance level).

Table 2. Analysis of risk for EG and CG in pre-test, YLS/CMI and SIFAR (Wilcoxon-Mann-Whitney, 2-tailed, $\alpha=.05$ )

\begin{tabular}{|c|c|c|c|}
\hline & Mann-Whitney U & $Z$ & Exact Sig. (2-tailed) \\
\hline \multicolumn{4}{|l|}{ YLS/CMI } \\
\hline Previous crimes & 15.00 & -1.92 & .08 \\
\hline Family context & 18.50 & -1.46 & .19 \\
\hline Education & 24.50 & -.81 & .45 \\
\hline Peer relations & 17.50 & -1.60 & .13 \\
\hline Substance abuse & 32.00 & .00 & 1.00 \\
\hline Leisure & 24.50 & -1.04 & .45 \\
\hline Personality & 29.00 & -.33 & .80 \\
\hline Attitudes & 26.50 & -.60 & .60 \\
\hline Total value & 28.00 & -.42 & .70 \\
\hline Risk level & 26.00 & -.69 & .69 \\
\hline \multicolumn{4}{|l|}{ SIFAR risk factors } \\
\hline Education & 29.00 & -.35 & .85 \\
\hline Employment & 32.00 & .00 & 1.00 \\
\hline Housing/Mobility & 32.00 & .00 & 1.00 \\
\hline Legal problems & 25.50 & -.71 & .55 \\
\hline Dissonance & 32.00 & .00 & 1.00 \\
\hline Poverty & 30.00 & -.23 & .89 \\
\hline Social net & 32.00 & .00 & 1.00 \\
\hline Social Security & 29.50 & -.28 & .86 \\
\hline Parenting & 28.50 & -.40 & .89 \\
\hline SIFAR total & 29.50 & -.26 & .82 \\
\hline \multicolumn{4}{|l|}{ SIFAR Protective } \\
\hline Family involvement & 32.00 & .00 & 1.00 \\
\hline High discipline & 24.00 & -1.46 & .47 \\
\hline Low punishment & 20.00 & -1.86 & .20 \\
\hline Low parent stress & 20.00 & -1.46 & .32 \\
\hline \multicolumn{4}{|l|}{ Management Factors } \\
\hline High supervision & 24.00 & -1.46 & .47 \\
\hline Good neighborhood & 20.00 & -1.46 & .32 \\
\hline Non-adolescent mother & 16.00 & -2.00 & .12 \\
\hline Prosocial peers & 24.00 & -1.12 & .57 \\
\hline Physical health & 32.00 & .00 & 1.00 \\
\hline Mental health & 32.00 & .00 & 1.00 \\
\hline Substance abuse & 32.00 & .00 & 1.00 \\
\hline
\end{tabular}

In the analysis of the association between SIFAR and YLS/CMI we compared the SIFAR and YLS/CMI items that are more closely related to each other, particularly the SIFAR parenting and its protective factors and the YLS/CMI family context. The analysis of the association between the post-test SIFAR and YLS/CMI results shows that SIFAR parenting 
has a large positive association with YLS/CMI family context $(r s=.93, p<.05)$ and YLS/CMI total value $(r s=.69, p$ $<.05)$. The SIFAR protective factors' involvement in family activities has a large negative correlation with YLS/CMI family context $(r s=-.53, p<.05)$ and YLS/CMI total value $(r s=-.56, p<.05)$, high discipline has a large negative correlation with YLS/CMI family context $(r s=-.86, p<.05)$ and YLS/CMI total value $(r s=-.67, p<.05)$. Low physical punishment has a moderate negative correlation with YLS/CMI family context $(r s=-.44, p<.05)$ and YLS/CMI total value $(r s=-.49, p<.05)$, low parental stress has a moderate negative correlation with YLS/CMI family context $(r s=-.39$, $p<.05)$ but a small negative correlation with YLS/CMI total value $(r s=-.16, p<.05)$. Since it is an SPJ tool, SIFAR total values are only used for research purposes and show a large positive correlation with YLS/CMI family context $(r s=.78, p$ $<.05)$ and YLS/CMI total value $(r s=.80, p<.05)$. The protective factors' total values have a large negative correlation with YLS/CMI family context $(r s=-.82, p<.05)$ and YLS/CMI total value $(r s=-.73, p<.05)$.

The sensitivity and discriminant capability of SIFAR was assessed by analyzing the differences in the risk and protective items between the EG and CG after the program (independent samples) and the in intra-group pre- and post-test differences (paired samples), comparing with YLS/CMI results.

The pre-test results show that there were no significant differences for risk between EG and CG (table 2). Regarding the post-test risk differences assessment between EG and CG, we can see that the YLS/CMI risk items family context ( $U$ $=.00 ; Z=-3.42, p=.00)$, education/employment $(U=12.00 ; Z=-2.16, p=.02)$, leisure $(U=7.00 ; Z=-2.84 ; p=.00)$, YLS total value $(U=11.50 ; Z=-2.16, p=.02)$, and YLS risk level $(U=13.50 ; Z=-2.04, p=.03)$ show a significant decrease of risk. In the YLS/CMI results, the effect size on EG for post-test $(r=.63)$ in the family context risk factor (which is directly targeted by the program) is considered a large effect size (Rosenthal et al., 2000) in the RRIP results.

Table 3. Analysis of risk and protective factors by YLS/CMI and SIFAR for EG and CG in post-test. Independent samples (Wilcoxon-Mann-Whitney, 1-tailed, $\alpha=.05$ )

\begin{tabular}{|c|c|c|c|c|}
\hline & Mann-Whitney U & $Z$ & $\begin{array}{l}\text { Exact Sig. } \\
\text { (1-tailed) }\end{array}$ & $\begin{array}{l}\text { Effect size } \\
(r)\end{array}$ \\
\hline \multicolumn{5}{|l|}{ YLS } \\
\hline Previous crimes & 15.00 & -1.92 & .12 & \\
\hline Family context & .00 & -3.42 & .00 & .86 \\
\hline Education & 12.00 & -2.16 & .02 & .54 \\
\hline Peer relations & 11.50 & -2.23 & .42 & \\
\hline Substance abuse & 28.00 & -1.44 & .35 & \\
\hline Leisure & 7.00 & -2.84 & .00 & .71 \\
\hline Personality & 22.50 & -1.01 & .17 & \\
\hline Attitudes & 16.50 & -1.68 & .14 & \\
\hline Total value & 11.50 & -2.16 & .02 & .54 \\
\hline Risk level & 13.50 & -2.04 & .03 & .51 \\
\hline \multicolumn{5}{|l|}{ SIFAR risk factors } \\
\hline Education & 18.00 & -1.93 & .07 & \\
\hline Employment & 28.00 & -.47 & .35 & \\
\hline Housing/Mobility & 28.00 & -.48 & .34 & \\
\hline Legal problems & 9.00 & -2.60 & .01 & .65 \\
\hline Dissonance & 27.00 & -.64 & .32 & \\
\hline Poverty & 24.00 & -.89 & .25 & \\
\hline Social net & 27.50 & -.69 & .37 & \\
\hline Social Security & 18.00 & -1.54 & .10 & \\
\hline Parenting & .00 & -3.60 & .00 & .90 \\
\hline SIFAR total & 7.50 & -2.58 & .01 & .65 \\
\hline \multicolumn{5}{|l|}{ SIFAR protective } \\
\hline Family involvement & 16.00 & -1.94 & .07 & \\
\hline High discipline & 8.00 & -3.00 & .00 & .75 \\
\hline Low punishment & 20.00 & -1.86 & .10 & \\
\hline Low parent stress & 20.00 & -1.86 & .10 & \\
\hline Protective total & 4.00 & -3.07 & .00 & .77 \\
\hline \multicolumn{5}{|l|}{ Management factors } \\
\hline High supervision & 8.00 & -3.00 & .00 & .75 \\
\hline Good neighborhood & 20.00 & -1.46 & .16 & \\
\hline Non-adolescent mother & 16.00 & -.2 .00 & .06 & \\
\hline Prosocial peers & 16.00 & -2.00 & .06 & \\
\hline Physical health & 30.00 & -.24 & .50 & \\
\hline Mental health & .00 & -3.57 & .00 & .89 \\
\hline Substance abuse & 26.00 & -.68 & .26 & \\
\hline
\end{tabular}

In the SIFAR assessment, the risk items legal problems $(U=9.00 ; Z=-2.60, p=.01)$ and parenting $(U=.00 ; Z=-3.60, p$ $=.00)$ show a significant difference between EG and CG. The SIFAR total $(U=7.50 ; Z=-2.58, p=.01)$ and the case 
management factor mental health $(U=.00 ; Z=-3.57, p=.00)$ also show a significant decrease of risk. The effect size for SIFAR total $(r=.65)$, legal problems $(r=.65)$, parenting $(r=.90)$ and mental health $(\mathrm{r}=.89)$, are all considered large effect sizes (Rosenthal et al., 2000), in the EG's RRIP results.

In respect of the SIFAR protective factors, the significant difference between EG and CG occurs in the items high discipline $(U=8.00 ; Z=-3.00, p=.00)$ and the protective total value $(U=4.00 ; Z=-3.07, p=.00)$. These and the management factor high supervision $(U=8.00 ; Z=-3.00, p=.00)$ increased with the protective factor high discipline having a large effect size .75, in the RRIP results (Table 3 ).

The analysis of the pre and post-test EG and CG paired samples showed the differences of each group respectively with and without the RRIP (Pakman, 2007) implementation. Regarding the EG, the data shows that the YLS/CMI parameters show a significant difference between the pre- and post- administration of RRIP in the items family context $(Z=-2.53, p$ $=.00, r=.63)$, education $(Z=-2.23, p=.02)$, leisure $(Z=-2.23, p=.02)$, total value $(Z=-2.64, p=.01)$ and the risk level $(Z=-2.53, p=.04)$, with a decrease of risk in post-test EG. In respect of the SIFAR risk factors, there are also significant differences in the items legal problems $(Z=-2.26, p=.02, r=.57)$, parenting $(Z=-2.54, p=.00, r=.64)$ and the total value $(Z=-2.53, p=.00, r=.63)$, as well as the case management factor mental health $(Z=-2.40, p=.01, r=.60)$. In the SIFAR protective factors there are no significant differences between pre and post-test (table 4). However, there is an increase in the protective factors family involvement $(Z=-2.00, p=.06)$ and high discipline $(Z=-2.00, p=.06)$, and in the case management risk factor high supervision $(Z=-2.00, p=.06)$, which are not significant but nonetheless produce a significant result in the total of protective value $(Z=-2.56, p=.00, r=.64)$, even though, as an SPJ tool, the SIFAR total values are only used for research purposes.

Table 4. Analysis of risk and protective factors by YLS/CMI and SIFAR of EG for pre- and post-test. Paired samples (Wilcoxon, 1-tailed, $\alpha=.05$ )

\begin{tabular}{|c|c|c|c|}
\hline YLS & $\begin{array}{l}Z \\
\end{array}$ & Exact Sig. (1-tailed) & Effect size \\
\hline Previous crimes & $.00^{\mathrm{c}}$ & 1.00 & \\
\hline Family context & $-2.53^{b}$ & .00 & .63 \\
\hline Education & $-2.23^{b}$ & .02 & .63 \\
\hline Peer relations & $-1.63^{\mathrm{b}}$ & .13 & \\
\hline Substance abuse & $-1.41^{b}$ & .25 & \\
\hline Leisure & $-2.23^{b}$ & .02 & .63 \\
\hline Personality & $-1.83^{\mathrm{b}}$ & .06 & \\
\hline Attitudes & $-1.60^{\mathrm{b}}$ & .13 & \\
\hline Total value & $-2.64^{b}$ & .01 & .66 \\
\hline Risk level & -2.53 & .04 & .63 \\
\hline \multicolumn{4}{|l|}{ SIFAR risk factors } \\
\hline Education & $-1.34^{\mathrm{a}}$ & .25 & \\
\hline Employment & $-1.41^{\mathrm{a}}$ & .25 & \\
\hline Housing/Mobility & $-1.34^{\mathrm{a}}$ & .25 & \\
\hline Legal problems & $-2.26^{\mathrm{a}}$ & .02 & .57 \\
\hline Dissonance & $-1.00^{\mathrm{a}}$ & .50 & \\
\hline Poverty & $-1.63^{\mathrm{a}}$ & .13 & \\
\hline Social net & $-1.34^{\mathrm{a}}$ & .25 & \\
\hline Social Security & $-1.89^{\mathrm{a}}$ & .06 & \\
\hline Parenting & $-2.54^{\mathrm{a}}$ & .00 & .64 \\
\hline SIFAR total & $-2.53^{\mathrm{a}}$ & .00 & .63 \\
\hline \multicolumn{4}{|l|}{ SIFAR protective } \\
\hline Family involvement & $-2.00^{\mathrm{b}}$ & .06 & \\
\hline High discipline & $-2.00^{\mathrm{b}}$ & .06 & \\
\hline Low punishment & $.00^{\mathrm{c}}$ & 1.00 & \\
\hline Low parent stress & $-2.24^{b}$ & .10 & \\
\hline Protective total & -2.56 & .00 & .64 \\
\hline \multicolumn{4}{|l|}{ Management factors } \\
\hline High supervision & $-2.00^{\mathrm{b}}$ & .06 & \\
\hline Good neighborhood & $.00^{\mathrm{c}}$ & 1.00 & \\
\hline Non-adolescent mother & $.00^{\mathrm{c}}$ & 1.00 & \\
\hline Prosocial peers & $-1.41^{b}$ & .25 & \\
\hline Physical health & $-1.00^{\mathrm{a}}$ & .50 & \\
\hline Mental health & $-2.40^{\mathrm{a}}$ & .01 & .60 \\
\hline Substance abuse & $-1.84^{\mathrm{a}}$ & .06 & \\
\hline
\end{tabular}

a. Based on positive ranks. ${ }^{b}$. Based on negative ranks. . The sum of negative ranks equals the sum of positive ranks.

The results of the CG paired in the pre- and post-test shown that there are no significant differences in any of the risk and protective factors (Table 5). 
Table 5. Analysis of risk and protective factors by YLS/CMI and SIFAR of CG for pre- and post-test. Paired samples (Wilcoxon, 1-tailed, $\alpha=.05$ )

\begin{tabular}{|c|c|c|}
\hline & $Z$ & Exact Sig. (1-tailed) \\
\hline \multicolumn{3}{|l|}{ YLS/CMI } \\
\hline Previous crimes & $-1.00^{b}$ & .50 \\
\hline Family context & $-1.41^{b}$ & .25 \\
\hline Education & $-1.00^{\mathrm{c}}$ & .50 \\
\hline Peer relations & $.00^{\mathrm{a}}$ & 1.00 \\
\hline Substance abuse & $.00^{\mathrm{a}}$ & 1.00 \\
\hline Leisure & $.00^{\mathrm{a}}$ & 1.00 \\
\hline Personality & $.00^{\mathrm{a}}$ & 1.00 \\
\hline Attitudes & $.00^{\mathrm{a}}$ & 1.00 \\
\hline Total value & $.00^{\mathrm{c}}$ & .63 \\
\hline Risk level & $-1.00^{\mathrm{c}}$ & .50 \\
\hline \multicolumn{3}{|l|}{ SIFAR } \\
\hline Education & $.00^{\mathrm{a}}$ & 1.00 \\
\hline Employment & $.00^{\mathrm{b}}$ & 1.00 \\
\hline Housing/Mobility & $-1.00^{c}$ & .50 \\
\hline Legal problems & $.00^{\mathrm{a}}$ & 1.00 \\
\hline Dissonance & $.00^{\mathrm{a}}$ & 1.00 \\
\hline Poverty & $-1.00^{\mathrm{b}}$ & .50 \\
\hline Social net & $.00^{\mathrm{a}}$ & 1.00 \\
\hline Social Security & $0.00^{\mathrm{a}}$ & 1.00 \\
\hline Parenting & $.00^{\mathrm{a}}$ & .75 \\
\hline SIFAR total & $.00^{\mathrm{a}}$ & .63 \\
\hline \multicolumn{3}{|l|}{ SIFAR protective } \\
\hline Family involvement & $.00^{\mathrm{c}}$ & 1.00 \\
\hline High discipline & $.00^{\mathrm{c}}$ & 1.00 \\
\hline Low punishment & $.00^{\mathrm{c}}$ & 1.00 \\
\hline Low parent stress & $-1.00^{\mathrm{a}}$ & .50 \\
\hline Protective total & $-1.00^{\mathrm{a}}$ & .50 \\
\hline \multicolumn{3}{|l|}{ Management factors } \\
\hline High supervision & $.00^{\mathrm{c}}$ & 1.00 \\
\hline Good neighborhood & $.00^{\mathrm{c}}$ & 1.00 \\
\hline Non-adolescent mother & $.00^{\mathrm{c}}$ & 1.00 \\
\hline Prosocial peers & $.00^{\mathrm{c}}$ & 1.00 \\
\hline Physical health & $.00^{\mathrm{a}}$ & 1.00 \\
\hline Mental health & $-1.00^{b}$ & .50 \\
\hline Substance abuse & $.00^{\mathrm{a}}$ & 1.00 \\
\hline
\end{tabular}

${ }^{a}$. Based on positive ranks. ${ }^{b}$. Based on negative ranks. ${ }^{c}$.The sum of negative ranks equals the sum of positive ranks.

\section{Discussion}

The clinical forensic use of SIFAR assessing a small sample of families of detained juvenile offenders was presented in this study. For this purpose, the efficiency of the RRIP (Pakman, 2007), a family risk reduction program in use in Portuguese juvenile forensic system, was analyzed using SIFAR and YLS/CMI. A pre- and post-test design with control and experimental group was used to assess its clinical effects. The actuarial risk assessment tool YLS/CMI was used for adolescent risk assessment and the SIFAR as an SPJ adolescent's family risk assessment tool.

No significant differences between the pre- and the post-test results were found for the CG by the YLS/CMI and SIFAR. Otherwise, YLS/CMI had several dimensions with significant differences between pre- and post-test in the EG, but only the family context dimension was analyzed because this is the specific context targeted by the RRIP (Pakman, 2007). The YLS/CMI post-test results show significant differences between EG and CG in the family context items inadequate discipline, inconsistent parenting and bad relationship with father and/or mother, but there is much less success in the difficulties in behavior control item. This means that although positive changes were made in parenting their efficacy could only be judged at the time of the adolescent domiciliary visits, because the adolescent was currently in detention. Understandably, as the adolescent was in detention the parents could not improve their perception about their ability to control the behavior of their children, but the other parenting interactions were implemented and assessed during their visits.

In SIFAR the assessment is based on parent strategies to deal with family circumstances, including parenting practices, in an effort to understand how family context variables are related to each other, with the parent-child relationships being especially relevant. The wider effect of the RRIP for the EG was found in the decrease of risk in parenting and legal problems factors and with the management factor mental health. However, for a $10 \%$ significance level, the risk items education and social security also show significant improvement differences between the EG and the CG, such as the 
protective factors family involvement, low physical punishment and low parental stress.

The interplay of risk and strength factors in the family of adolescent offenders is a relevant issue because family quality relations and living conditions are relevant indicators of an adolescent's risk of offending behavior (Andrews \& Bonta, 2010; Farrington, 2004; Goodman \& Adler, 2010; Loeber et al., 2008; McGuire, 2004; Welsh \& Farrington, 2010). Actually, the family is the spatial and temporal arena where children and adolescents live and absorb the affective, emotional and behavioral dimension of human experience. It is where they build up the identity, social roles and feeling of belonging to a certain family group (Alarcão, 2002). With such an important socialization context, we can understand the impact of disturbed relations among family members, whose clinical relevance is apparent not only in the adolescent's criminal behavior (Farrington, 2004; Goodman \& Adler, 2010; Henggeler \& Schoenwald, 2011; Loeber et al., 2008; McGuire, 2004; Welsh \& Farrington, 2010) but also in several other youth mental health risk conditions (Helgeland \& Torgersen, 2004; Lemos, 2007; Schmidt \& Maras, 2001; Serbin \& Karp, 2004). Families characterized by instability and organizational chaos, with inconsistent rules and relationships, exhibit a dynamic diametrically opposed to adolescent development needs (Alarcão, 2002; Ausloos, 1996; Helgeland \& Torgersen, 2004; Serbin \& Karp, 2004). Adolescents therefore look for external references thus disrupting the attachment process and increasing relational fragility (Alarcão, 2002), as several studies on adolescent offenders have recognized (Farrington, 2004; Loeber et al., 2008; Welsh \& Farrington, 2010).

When assessing the complexity of these relational familial disturbed patterns it is useful to design instruments which allow to an integrative intervention plan where individual and family criminogenic needs are targeted and responsivity issues taken into account (Andrews \& Bonta, 2010; Loeber et al., 2008). Therefore, the SIFAR shows to be a valuable instrument in family risk assessment, if applied by trained professionals. It seems to be particularly useful to assess the multiple family conditions, namely, the parenting practice strategies, the strategies to cope with adolescent's legal problems, the family mental health issues and the family strengths/protective factors.

Analyzing the use of SIFAR and YLS/CMI in clinical practice as a fourth generation risk instruments (Andrews \& Bonta, 2010), the findings show that both tools assess the complementary aspects of an adolescent offender's family in different degrees. While its actuarial design means that the YLS/CMI assesses the presence/absence of some family parenting issues and their impact on the risk level, SIFAR clarifies the family strategies which might define the presence/absence of the specific family risk covering the contextual variables with family relevance, the family dynamics and the quality of affective and emotional relationships. This understanding of family sheds some light on its weaker areas and its potential to change in the directions that might decrease the risk of adolescent's involvement in criminal practices and proposes appropriate, direct, interventions (Gordon, 2002; Loeber et al., 2008). SIFAR is based on the assessment of strategies and it can determine what type of family's intervention it is needed, with more sensitivity. This is a relevant issue because family conditions are not merely present/absent realities, they occur in several degrees and involve specific interplays and patterns between individual, grupal and contextual characteristics. This is why the detailed information on the assessment of an adolescent offender's family is needed (Dembo et al., 2001; Gordon, 2002; Loeber et al., 2008) and SIFAR demonstrated that one can analyze why, how, and to what extent the family risk and protective factors are present and combine.

The association between the family items in both these risk assessment tools demonstrates the coherence between both instruments in their clinical findings. In particular, the positive strong association between SIFAR parenting and YLS/CMI family context and their total values, as along with the negative strong correlations between SIFAR protective and protective total and YLS/CMI family context and total values, express these converging results.

The results of this study also shed some light about the use of these risk assessment tools in active prevention in forensic practice (Loeber et al., 2008) and risk and neglect field (Helgeland \& Torgersen, 2004; Serbin \& Karp, 2004). This integrative prevention framework can decrease the risk and activate the family's resources. It will therefore probably contribute to the lower involvement of adolescents in severe criminal behavior since it addresses the human service objectives of the Risk, Need and Responsivity model (Andrews \& Bonta, 2010).

\section{Conclusion}

This study is based on a quasi-experimental design that aims to evaluate the SIFAR as an adolescent offender family risk tool. Using the SIFAR and the YLS/CMI in pre- and post-test to assess the efficiency of the RRIP, the main results show that this intervention program can improve relational patterns and parent strategies to deal with their children. The results also highlight the qualities of the SIFAR as a risk assessment tool. Although the results are promising they must be viewed along with the study's limitations: it uses a small convenience sample comprising families of male adolescents in custody; the post-test was gathered shortly after the program's implementation (three months), and there is no assessment of the information related to recidivism. These limitations do not allow the generalization of results, but they hint the continuation of the validation process of SIFAR, by using a larger random sample of male and female adolescent 
offenders and juveniles under probation in a longitudinal study with a long time range of risk and protective assessment.

\section{Compliance with Ethical Standards}

This study was not funded. All procedures performed in this study were in accordance with the ethical standards of the institutional and/or national research committee and with the 1964 Helsinki declaration and its later amendments or comparable ethical standards. Informed consent was obtained from all individual participants included in the study.

\section{References}

Alarcão, M. (2002). Family (Im)balances. Coimbra: Quarteto Editora.

Andrews, D., \& Bonta, J. (2010). The psychology of criminal conduct (5th ed.). Cincinnati: Anderson Publishing Co.

Ausloos, G. (1996). The Competence of Families, Time, Chaos, Process. Lisboa: Climepsi Editores.

Cohen, J. (1988). Statistical Power Analysis for the Behavioral Sciences. Erlbaum: Hillsdale, NJ.

Constanzo, M., \& Krauss, D. (2012). Predicting violent behaviour: the psychology of risk assessment. In M. Constanzo, \& D. Krauss (eds.), Forensic and Legal Psychology. Psychological Science Applied to Law (pp 299-324). Worth Publishers, New York.

Dembo, R., Ramírez-Garnica, G., Rollie, M., Schmeidler, J., Livingston, S., \& Hartsfield, A. (2001). A long-term impact of a family empowerment intervention on youth recidivism. Journal of Offender Rehabilitation, 33(1), 33-58. https://doi.org/10.1300/J076v33n01_02

Farrington, D. (2004). The study of the development of Cambridge delinquency: main results of the first 40 years. In A.C. Fonseca (ed.), Comportamento antissocial e família, uma abordagem científica (pp 73-132). Coimbra: Livraria Almedina.

Farrington, D., \& Welsh, B. (2007). Effective programmes to prevent delinquency. In J. Adler, \& J. Gray (eds.), Forensic Psychology, Concepts, Debates and Practice (pp 378-396). New York: Willan Publishing.

Goodman, A., \& Adler, J. (2010). Parenting projects, justice and welfare. In J. Adler, \& J. Gray (eds.), Forensic Psychology, Concepts, Debates and Practice (pp 404-422). New York: Willan Publishing.

Gordon, D. A. (2002). Intervening with families of troubled youth: functional family therapy and parenting wisely. Chichester: John Wiley \& Sons Ltd.

Helgeland, M., \& Torgersen, S. (2004). Developmental antecedents of borderline personality disorder. Comprehensive Psychiatry, 45, 138-147. https://doi.org/10.1016/j.comppsych.2003.09.001

Henggeler, S., \& Schoenwald, S. (2011). Evidence-based interventions for juvenile offenders and juvenile justice policies that support them. Social Policy Report, 25(1), 1-20.

Hoge, R., Andrews, D., \& Leschied, A. (2002). Youth Level of Service/Case management Inventory. New York: Multi-Health Systems, North Tonawanda.

Kury, H., \& Woessner, G. (2002). The family and deviant behavior of young people. In A. C. Fonseca (ed.), Comportamento Anti-social e Família, Uma Abordagem Cientifica (pp 181-212). Coimbra: Livraria Almedina.

Le Blanc, M., \& Janosz, M. (2002). Family regulation of delinquent conduct in adolescents. In A. C. Fonseca (ed.), Comportamento Anti-social e Família, Uma Abordagem Cientifica (pp 37-87). Coimbra: Livraria Almedina.

Lemos, I. (2007). Family, psychopathology and resilience in adolescence: from psychosocial risk to delinquent course (Unpublished doctoral dissertation). Faculdade de Ciência Humanas e Sociais da Universidade do Algarve, Faro.

Lipsey, M. (2009). The primary factors that characterize effective interventions with juvenile offenders: A meta-analytic overview. Victims and Offenders, 4, 124-147. https://doi.org/10.1080/15564880802612573

Loeber, R., Farrington, D., Stouthamer-Loeber, M., \& White, H. (2008). Violence and serious theft. Development and prediction from childhood to adulthood. New York: Taylor \& Francis Group, LLC.

McGuire, J. (2004). Understanding psychology and crime. Perspectives on theory and action. New York: Open University Press.

Pakman, M. (2007). Risk Reduction and the Micropolitics of Social Justice in Mental Health Care. In E. Aldarondo (ed.), Advancing Social Justice Through Clinical Practice (pp 151-173). New Jersey: Lawrence Eribaum Associates.

Rosenthal, R., Rosnow, R., \& Rubin, D. (2000). Contrasts and effect sizes in behavioral research: a correlational approach. Cambridge: Cambridge University Press.

Ruiter, C. D., \& Nicholls, T. (2011). Protective Factors in Forensic Mental Health: A New Frontier. International Journal 
of Forensic Mental Health, 10(3), 160-170. https://doi.org/10.1080/14999013.2011.600602

Santos, D., \& Alberto, I. (2015). Developing a family risk assessment tool in adolescent offenders: an exploratory study. Child and Adolescent Social Work Journal, 33(2), 103-113. https://doi.org/10.1007/s10560-015-0409-1

Santos, D., Alberto, I., \& Marques, C. (2016). The Structured Interview of Family Assessment Risk: Convergent validity, inter-rater reliability and structural relations. Child and Adolescent Social Work Journal. Advance online publication. https://doi.org/10.1007/s10560-016-0444-6

Schmidt, M., \& Maras, A. (2001). Principles of child and adolescent psychiatry. In Smelser, N. J. \& Balter, P. B. (eds.), International Encyclopedia of the Social and Behavioral Sciences (pp 1676-1682). New York: Elsevier. https://doi.org/10.1016/B0-08-043076-7/03713-X

Serbin, L., \& Karp, J. (2004). The intergenerational transfer of psychosocial risk: mediators of vulnerability and resilience. Annual Review of Psychology, 55, 333-390. https://doi.org/10.1146/annurev.psych.54.101601.145228

Vogel, V. D., Robbé, M., Ruiter, C. D., \& Bouman, Y. (2011). Assessing Protective Factors in Forensic Psychiatric Practice: Introducing the SAPROF. International Journal of Forensic Mental Health, 10(3), 171-177. https://doi.org/10.1080/14999013.2011.600230

Wasserman, G., Keenan, K., Tremblay, R., Coie, J., Herrenkohl, T., Loeber, R., \& Petechuck, D. (2004). Risk Factors and Protective Factors in Childhood Delinquency. Infância e Juventude, Revista do Instituto de Reinserção Social, 4, 51-86.

Welsh, B., \& Farrington, D. (2010). Effective programmes to prevent delinquency. In J. Adler, \& J. Gray (eds.), Forensic Psychology, Concepts, Debates and Practice, (pp 378-403). New York: Willan Publishing.

\section{Copyrights}

Copyright for this article is retained by the author(s), with first publication rights granted to the journal.

This is an open-access article distributed under the terms and conditions of the Creative Commons Attribution license which permits unrestricted use, distribution, and reproduction in any medium, provided the original work is properly cited. 